\title{
Afatinib, a lung cancer inhibitor of ErbB family
}

\author{
Pasqualino de Antonellis
}

Received: 27 March 2014 / Accepted: 31 March 2014 / Published online: 13 April 2014

(C) Springer-Verlag Berlin Heidelberg 2014

In this issue, Modjtahedi and colleagues present the preclinical profile of "afatinib", a new promising molecule, for the treatment of molecularly defined subgroups of patients with advanced lung cancer. Lung cancer is the leading cause of cancer-related mortality worldwide, and it results in more than 1 million deaths per year. The main types of lung cancer are small-cell lung carcinoma (SCLC), also called "oat cell cancer", and non-small-cell lung carcinoma (NSCLC), occurring in about $85 \%$ of lung cancer patients (Reck et al. 2013). Generally, at diagnosis, more than $80 \%$ of NSCLC cases are in advanced stage (IIIB or IV) for which systemic chemotherapy remains the standard care but often provides only marginal improvement in survival (Sequist et al. 2013). In more than half of the patients with NSCLC, epidermal growth factor receptor (EGFR)-dependent pathway plays an important role driving the development and progression of epithelial cells (Yang et al. 2013). Afatinib [BIBW 2992;N-[4-[(3chloro-4-fluorophenyl)amino]-7-[[(3S)-tetrahydro-3-furanyl] oxy]-6-quinazolinyl]-4-(dimethylamino)-2-butenamide] is an ATP-competitive anilinoquinazoline derivative harboring a reactive acrylamide group and belongs to a family of new small molecules which bind covalently the tyrosine kinase domain of ErbB receptors acting as tyrosine kinase inhibitors (TKIs) (Singh et al. 2011). Differently from the first generation of these molecules (erlotinib and gefitinib), afatinib, through its covalent bond, irreversibly blocks enzymatically active ErbB receptor family members (Solca et al. 2012).

\footnotetext{
P. de Antonellis

Dipartimento di Medicina Molecolare e Biotecnologie Mediche,

Università 'Federico II' di Napoli, Naples, Italy

P. de Antonellis $(\bowtie)$

Centro di Ingegneria Genetica e Biotecnologie Avanzate (CEINGE), Naples, Italy

e-mail: deantonellis@ceinge.unina.it
}

The authors have outlined the mechanisms of ERB inhibition by afatinib, underlining the capability of this molecule to inhibit both the spontaneous EGF-induced autophosphorylation of EGFR and the EGFR stimulated by its ligands, in the low nanomolar range.

Furthermore, the drug potency was observed both in wildtype and EGFR mutations revealed in several cancer cell types, including L858R, which occurs in EGFR-mutant patients with a frequency of approximately $43 \%$, and in a "second-site mutation" T790M, which can be detected in $50 \%$ and more lung cancers patients that have developed an acquired resistance to erlotinib or gefitinib.

Although preclinical experiments suggest the ability of afatinib to counteract tumorigenesis driven by T790M mutation, in clinical trials, there are doubts related to its full efficacy, showing minor expected improvements in patient response, similarly to the other EGFR inhibitors which can also cause resistance by prolonged exposure (Brugger and Thomas 2012; Gainor and Shaw 2013). In viewing cancer as an evolving process, it is reasonable to think that the ability to evade drugs, by neoplastic disease, might be associated with the development of new features. Thus, tailored drugs are able to eradicate cancer cells harboring the "targetable marker" but often produce resistance mechanisms causing only partial and temporary responses in patients. To this end, it would be of note to cite unambiguous studies, analyzing in details those targeted therapies and the crucial contribution of environmental factors to treatment responses and answering the question on how cancer is able to counteract those therapies (Yao et al. 2010; Sun et al. 2012; Weizman et al. 2013), thus definitively suggest the existence of a further layer in the complexity of cancer-drug resistance. Therefore, we might question whether these tailored drugs are the best choice for cancer therapy or whether the clinical use of molecular-targeted therapy treatment should be taking into the account the possibility of adjunctive therapies, based on the unique genetic-driven biology in each patient. 
To this end, the authors have analyzed the combinatorial use of afatinib with other inhibitors targeting both ErbB signaling pathway and/or specific downstream molecules of other signaling pathways, e.g., MEK, Akt, PI3K, mTOR, or STAT3, showing cases where afatinib alone had little effect on cell survival, while in the presence of another inhibitor, which did not affect survival on its own, became more potent. Prospectively, we should stay tuned for more details about these trials that would result in a benefit for patients. The data presented by Modjtahedi and colleagues refer that the greatest effort to the development of new anticancer therapies should be directed to the combinatorial use of existing drugs, rather than in searching new molecules, and also towards a more individualized view of molecular alteration that will likely might influence stratification of patients by physicians. Further refinement of these studies on combinatory treatment will surely help the management of patients.

As a drug discovery effort, afatinib presents several issues of discussions, telling a true story which outlines the difficulties encountered from the new molecule's idea till its efficacy and use in clinical trial.

The long list of examples provided by the authors demonstrate that afatinib has ample opportunities for combinations with other targeted agents, foreseeing that this molecule might be eligible for future appropriate treatment regimens, that should lead to new routes of attaining durable responses.

\section{References}

Brugger W, Thomas M (2012) EGFR-TKI resistant non-small cell lung cancer (NSCLC): new developments and implications for future treatment. Lung Cancer 77:2-8
Gainor JF, Shaw AT (2013) Emerging paradigms in the development of resistance to tyrosine kinase inhibitors in lung cancer. J Clin Oncol: Off J Am Soc Clin Oncol 31:3987-3996

Reck M, Heigener DF, Mok T, Soria JC, Rabe KF (2013) Management of non-small-cell lung cancer: recent developments. Lancet 382:709719

Sequist LV, Yang JC, Yamamoto N, O’Byrne K, Hirsh V, Mok T, Geater SL, Orlov S, Tsai CM, Boyer M, Su WC, Bennouna J, Kato T, Gorbunova V, Lee KH, Shah R, Massey D, Zazulina V, Shahidi M, Schuler M (2013) Phase III study of afatinib or cisplatin plus pemetrexed in patients with metastatic lung adenocarcinoma with EGFR mutations. J Clin Oncol: Off J Am Soc Clin Oncol 31:33273334

Singh J, Petter RC, Baillie TA, Whitty A (2011) The resurgence of covalent drugs. Nat Rev Drug Discovery 10:307-317

Solca F, Dahl G, Zoephel A, Bader G, Sanderson M, Klein C, Kraemer O, Himmelsbach F, Haaksma E, Adolf GR (2012) Target binding properties and cellular activity of afatinib (BIBW 2992), an irreversible ErbB family blocker. J Pharmacol Exp Ther 343:342-350

Sun Y, Campisi J, Higano C, Beer TM, Porter P, Coleman I, True L, Nelson PS (2012) Treatment-induced damage to the tumor microenvironment promotes prostate cancer therapy resistance through WNT16B. Nat Med 18:1359-1368

Weizman N, Krelin Y, Shabtay-Orbach A, Amit M, Binenbaum Y, Wong RJ, Gil Z (2013) Macrophages mediate gemcitabine resistance of pancreatic adenocarcinoma by upregulating cytidine deaminase. Oncogene. doi:10.1038/onc.2013.357

Yang JC, Hirsh V, Schuler M, Yamamoto N, O’Byrne KJ, Mok TS, Zazulina V, Shahidi M, Lungershausen J, Massey D, Palmer M, Sequist LV (2013) Symptom control and quality of life in LUX-Lung 3: a phase III study of afatinib or cisplatin/pemetrexed in patients with advanced lung adenocarcinoma with EGFR mutations. J Clin Oncol: Off J Am Soc Clin Oncol 31:3342-3350

Yao Z, Fenoglio S, Gao DC, Camiolo M, Stiles B, Lindsted T, Schlederer M, Johns C, Altorki N, Mittal V, Kenner L, Sordella R (2010) TGF-beta IL-6 axis mediates selective and adaptive mechanisms of resistance to molecular targeted therapy in lung cancer. Proc Natl Acad Sci U S A 107: $15535-15540$ 